\title{
Foetal Neuro-Protection-Role of Magnesium Sulphate
}

\section{Saima Perveen}

Pre maturity (delivery before 37 weeks of gestation) is one of the leading causes of perinatal death. ${ }^{1,2}$ An estimated 15 million babies are born pre mature every year in Pakistan. ${ }^{2,3}$ Pakistan is on $7^{\text {th }}$ number, among the top ten countries with highest rate of pre mature births per 100 live births, i-e; $15.8 \%$.

Over the past few years there is increasing trend in pre term births, the possible reason for this includes rising number of sub fertility treatment leading to multiple gestations, increase in maternal age, increase obesity leading to medical disorders like, pregnancy induced hypertension $(\mathrm{PIH})$, gestational diabetes Mellitus (GDM), and changes in the obstetrics practices such as more caesarean sections before term. ${ }^{2,45}$

Prematurity leads to breast feeding problems, temperature regulation, neurological disabilities, respiratory distress and more chances of infection and metabolic disorders. Preventing death and complications from pre maturity starts with healthy pregnancy and antenatal care. In case of pre term labour, World Health Organization (WHO) has developed guidelines to take care, includes ante natal steroids, magnesium sulphate administration to prevent neurological impairment and shift to the hospital with all the facilities available to take care of such pre term babies, such as thermal care, feeding support, kangaroo mother care, safe oxygen care and other treatment to help the babies breath. ${ }^{5,6}$

It was first time in 1980s when two studies published that preterm babies delivered to mothers with eclampsia had a lower risk of adverse neurological outcome then gestational age matched neonates born to mothers without preeclampsia. $^{3}$ Several researches started to know the cause and then in 1995 the data derived from California cerebral palsy project demonstrated an association between antenatal magnesium sulphate administrations prior to preterm birth and reduce incidence of cerebral palsy among infants born $<1500 \mathrm{gms}^{7}$

Correspondence: Dr Saima Perveen

Assistant Professor Gynae \& Obs Department,

Saidu Teaching Hospital Swat

Cell: 0333-9144880 Email:drhadi78@gmail.com

Received: December12th, 2020 , Accepted: February 12, 2021
From 2002 to 20085 randomised controlled trial studied magnesium sulphate for foetal neuroprotection and in 2009 a publication of three metaanalysis, all concluded that magnesium sulphate for neuro-protection decreases risk of childhood cerebral palsy.

Magnesium sulphate is an intra cellular cation essential for normal cellular function. It is an important cofactor for more than 300 enzymatic reactions. ${ }^{5}$ It is stored in bones, muscles and soft tissues. Its haemostasis is controlled by intestinal absorption, bone storage and renal excretion. Magnesium has an inhibitory effects on neuronal synopsis leading to its use is an anti convulsant particularly in eclamptic seizure. ${ }^{5}$ As an endogenous calcium antagonist, magnesium sulphate regularizes neuronal synopsis. It antagonizes calcium at pre-synoptic junction reducing acetyle choline surge and stimulation at neuro-muscular junction. It has voltage dependant block of $\mathrm{N}$-methyle de-aspartate receptor. ${ }^{5}$ These receptors are abundant in preterm white matter so it may be the mechanism that magnesium sulphate reduces neurological impairment in pre mature babies, if administered ante-natally to the mother.

Magnesium sulphate is administered intravenously or intramuscularly as a loading dose followed by maintenance dose. Intravenous administration of loading dose is $4 \mathrm{gm}$ IV diluted stat, followed by $1 \mathrm{gm}$ IV per hour in infusion of $0.9 \%$ saline. ${ }^{8}$ Intramuscular regime includes $4 \mathrm{gm}$ diluted IV stat and $5 \mathrm{gm}$ in each buttock followed by $5 \mathrm{gm}$ in alternate buttocks every 4 hourly. Minor side effects include hot flushes, nausea, vomiting and light-headedness, when given in therapeutic dose. Serious side effects are loss of patellar reflexes, respiratory depression and cardiac arrest. So whenever magnesium sulphate is given, the patient is observed for patellar reflexes, respiratory rate, blood pressure monitoring and urine output. ${ }^{8}$ Monitoring of the magnesium sulphate levels in serum is not recommended but if urine output is less than $30 \mathrm{ml} /$ hour, loss of patellar reflexes and dropping of blood pressure more than $15 \mathrm{mmh}$ from baselines then monitoring of serum magnesium levels are advised. In case of sign and symptoms of magnesium sulphate toxicity like; arrhythmias, 
hypotonia or oliguria one should call for medical help. The immediate management will be to give 8 to 12 litres of oxygen, calcium gluconate, do ECG to exclude heart block serum electrolytes and serum magnesium levels. ${ }^{8}$

Magnesium sulphate has promising results in prevention of cerebral palsy, and if one prevents a single case, can spare a lot of financial burden on family and government. Similarly it is a safe drug used for decades for the prevention and treatment of eclampcia. Now it is gaining popularity for prevention of cerebral palsy in pre term and premature babies, giving hopes to parents to have a normal healthy baby.

\section{REFERENCES}

1. Magee L, Sawchuck D, Synnes A, Dadelszen PV. The Magnesium Sulphate for Fetal Neuroprotection Consensus Committee; SOGC Maternal Fetal Medicine Committee. Magnesium Sulphate for Fetal Neuroprotection. SOGC Clinical Practice Guideline No. 258, May 2011. J Obstet Gynaecol Can 2011;33(5):516-529.

2. Lingam I, Robertson NJ. Magnesium as a Neuroprotective Agent: A Review of Its Use in the Fetus, Term Infant with Neonatal Encephalopathy, and the Adult Stroke Patient Dev Neurosci 2018;40:112-116 DOI: $10.1159 / 000484891$

3. Chollat C, Sentilhes L, Marret S. Fetal Neuroprotection by Magnesium Sulfate: From Translational Research to Clinical Application. Front. Neurol. 2018;9:247.1-7 doi: 10.3389/fneur.2018.00247

4. Galinsky R, Dean JM, Lingam I, Robertson NJ, Mallard $C$, Bennet $L$ et al. A Systematic Review of Magnesium Sulfate for Perinatal Neuroprotection: What Have We Learnt From the Past Decade? Front. Neurol. 2020;11:449.1-14 doi: 10.3389/fneur.2020.00449

5. Effect of Magnesium Sulfate Given for Neuroprotection Before Preterm Birth Crowther CA, Hiller JE, Doyle LW, Haslam RR. JAMA 2003; 290(200:2669-76

6. Chollat C, Marret S. Magnesium sulfate and fetal neuroprotection: overview of clinical evidence. Neural Regen Res 2018;13(12):2044-2049. doi:10.4103/1673-5374.241441

7. Magee L, Sawchuck D, Synnes A, Dadelszen PV. Magnesium Sulphate for Fetal Neuroprotection. J Obstet Gynaecol Can 2011;33(5):516-529.

8. Magnesium Sulphate to prevent cerebral palsy following pre term birth. Scientific Impact Paper No.29, August 2011. Royal College of Obstetricians \& Gynaecologists.1-7. 